\title{
A Fresh Start of Nuclear Safety Regulation and International Perspective
}

\author{
Commissioner, Nuclear Regulation Authority, Kenzo Oshima
}

\begin{abstract}
Reluctance is no justification for a failure to humbly acknowledge and explain that the Fukushima Nuclear Accident was a man-made disaster. Inward-looking attitudes should be cast aside and every possible effort must be made to rebuild a safety culture. Soul-searching into the Fukushima Accident must not end up being superficial. The operational system and human resource infrastructure urgently need to be reinforced by the Nuclear Regulation Authority and its Secretariat to deal with the country's growing international obligations to implement the necessary security, safeguard, and safety (3S) measures comprehensively.
\end{abstract}

\section{Introduction}

Almost three years have passed since the accident at the Fukushima Daiichi Nuclear Power Plant, operated by the Tokyo Electric Power Company (TEPCO) (hereinafter referred to as the "Fukushima Accident"). Even after the cold shutdown of its reactors announced in December 2011, thorny problems such as the treatment of contaminated water, the decommissioning process, and other medium- to long-term challenges loom large across the country.

Meanwhile, newly established in September 2012, the Nuclear Regulation Authority (NRA) took the first step toward fundamental reform of the public administration of nuclear safety amid many challenges. In the mission statement finalized shortly after its establishment, the NRA upheld as one of its five principles: To remain a transparent and open organization that respects the diverse opinions voiced in Japan and overseas while avoiding isolation and self-righteousness. This principle is the result of much soul-searching over the past mistakes including a cavalier attitude toward international standards and collaboration.

On this occasion, the NRA assumed a centralized role and responsibility for so-called " 3 S" measures: ensuring nuclear Security against terrorism and other hazards; implementing Safeguard measures against nuclear proliferation; and promoting nuclear Safety. The NRA's scope of responsibility was thus expanded to handle a greater number of international assignments of a wider variety, adding new challenges for the NRA.

This commentary attempts to describe the current state of the NRA with a focus on its

DOI : $10.15669 /$ fukushimainsights.Vol.3.68

(C) 2021 Atomic Energy Society of Japan. All rights reserved.

Originally published in Journal of the Atomic Energy Society of Japan (ISSN 1882-2606), Vol. 55, No. 11, p. 634-638 (2013)

in Japanese. (Japanese version accepted: August 30, 2013) 
international aspects and assignments. The opinions and views presented herein are those of the author and not necessary of the NRA.

\section{Active International Attention and Interests}

Many countries remain keenly interested in the Fukushima Accident because it is the major nuclear accident that occurred since the Chernobyl Accident of 1986. Their interests cover a wide range of issues, including the following: the causes of the accident; how the safety of spent fuel pools and damaged reactors is being ensured; lessons that should be learned; the principles and substance of new regulatory standards for nuclear safety; whether, and when, nuclear power plants will resume operation in Japan with the end of the current shutdown; how the contaminated water that continues to build up would be treated; how the decommissioning and decontamination work should be handled; how nuclear regulatory institutions are being reformed; trends in public opinion over nuclear energy issues; and the future of Japan's nuclear policy in relation to the export of power plants and nuclear fuel cycle.

Such a wide-ranging international attention has been shown in the recent numerous international conferences and workshops focused on the Fukushima Accident, in some of which the author had the opportunity to participate. They include lectures and panel discussions held at a Science and Technology in Society (STS) forum organized by an NPO (October 2012, Kyoto); the trilateral senior regulators meeting from South Korea, China, and Japan (November 2012, Seoul); the ministerial meeting on nuclear safety held in Fukushima and organized by the International Atomic Energy Agency (December 2012, Fukushima); IAEA's meeting of nuclear safety regulators (April 2013, Ottawa); IAEA's expert meeting (May 2013, Vienna); and a meeting of safety regulators from Europe (ENSREG, June 2013, Brussels). In addition, Japanese experts from the NRA, JNES, JAEA, TEPCO, and academic societies have also participated in the relevant meetings in the United States and France, as well as those hosted by the NEA of the OECD.

\section{Sharing Information with the Rest of the World}

Close attention is naturally directed at the remarks made by participants from Japan, the country that experienced the recent nuclear accident, regarding the specific information they provide and how they present it. There would be little problem if those participants share their personal opinions and observations freely in their individual capacity. However, when they speak representing the government or any authoritative organization and explain or respond to questions with some background authority, then the matter would become not so simple or easy.

In the wake of the Fukushima Accident and up to now, a number of accident reports have been issued in Japan, by the Diet, the national government, TEPCO, the private sector group, the Atomic Energy Society of Japan, respectively. On which of them to relay for presentation? In my case, I have relied mainly on the facts and findings presented in the Diet investigation report published by the Fukushima Nuclear Accident Independent Investigation Commission (NAIIC). This investigation commission was organized by the National Diet and I had the privilege of serving as its member. Now generally known as the "Kurokawa Report," picking the name of the NAIIC's Chairperson, this voluminous report has been swiftly translated into 
English in its entirety and shared with the rest of the world. As a result, this report seems to have been widely read by interested experts overseas and well received, in part due to its detailed analysis and evaluations.

Often in discussions at these meetings or during coffee breaks, a wide range of relevant questions are asked by the participants, including the following:

(a) Could the accident have been prevented, if so, how?;

(b) Why did Japan, aware of its high risks and vulnerability by exposure to earthquakes, end up building so many nuclear power plants?;

(c) How were the risks calculated when constructing multiple reactors at one site?;

(d) What impacts did the earthquake and tsunami have each as the cause of the accident?;

(e) What made the difference between the escalation into a severe accident at the Fukushima Daiichi Nuclear Power Plant on the one hand, and the avoidance of such an accident at the three power stations in its vicinity, namely at Onagawa, Fukushima Daini, and Tokai Daini, on the other hand?;

(f) How will the regulatory system and crisis management be improved in a postFukushima Japan?; and

(g) Did the evacuation of residents work out well? What were the bottlenecks, if any?

Such questions and observations coming from the participants no doubt reflect their own serious concerns with respect to their own countries, as well as the results of their in-depth studies of the issues.

At the same time, some comments were also heard to the effect that while fully sympathizing with the Japanese about the extent of the shock from the Fukushima Accident, whether the new regulatory standards that are being developed might be handled either too hastily or unrealistically severely.

It is frankly admitted that for someone like this author, with a liberal arts background, the task to provide an adequate account of the complex nuclear accident, in its scientific and technical aspects for the benefit of overseas experts and the media, is next to impossible. The task may become slightly less complicated when it comes to explaining the human, structural, or organizational aspects of the issues, and the indirect causes and underlying factors of the accident, although that is still no easy thing to do.

That said, any account of the causes and underlying factors of the Fukushima Accident cannot be complete or credible without touching upon the central issue, namely, the weaknesses in the prevailing nuclear safety culture or the so-called "safety mythology" in Japan. But, frankly speaking, to do this in front of foreign nuclear experts could entail certain hesitation or uneasiness because it comes down to revealing what amounts to "false assumptions" and "national blunders" that Japan had made before the accident. They include perceptions, for example, that "nuclear power plants are safe and carry no risks," "extended power loss need not to be worried because of the country's well-established and reliable power supply infrastructure," "severe accidents will not happen, and therefore appropriate countermeasures can be left to the power utilities," etc.

However, the fact is that the Fukushima Accident was a rare major nuclear accident that caused anxieties, not only in Japan but also in the neighboring countries and beyond. And the concerns created will continue to arrest the international attention in the future. This is the reason why convincing accounts and explanations must be provided, and repeated, both in direct communications from Japan and in the remarks made at international conferences and exchanges. Japan should humbly share the lessons learned after much soul-searching with the international community, and set a positive example by implementing those lessons to reform itself. This is no doubt what the international community expects of Japan. Such a realization 
should prevail over any perceived sense of hesitation or shame. A sincere attitude and commitment in correcting what went wrong will be the surest way for Japan to recover from its damage and regain international trust for the country.

Having said that, I must frankly admit that there is no pleasure or satisfaction felt even when someone from the audience in international meetings comes forward and compliments by saying, "Your frank and straightforward briefings today were extremely informative and helpful." Far from any pleasure, I found myself always left with some uneasy or mixed feelings. Thankfully, perhaps out of sympathy or courtesy for the country that suffered the terrible disaster, it seemed participants tended to avoid asking the sort of questions that are too embarrassing or annoying to the Japanese. In this context, on one, two or three occasions I recall one particular comment by a participant, not in the meeting room but during casual conversations outside the meeting room, who said, to the effect, "I heard you express remorse over Japan's lax nuclear safety regulations and weak safety culture. Even so, I find it very disappointing that, of all countries, a technological powerhouse like Japan made such mistakes, particularly after experiencing the tragedies of Hiroshima and Nagasaki." As a citizen who comes from Hiroshima myself, I had no word to respond to it.

\section{Human Factors}

The Kurokawa Report clearly concludes that the Fukushima Accident must be understood as a "man-made" disaster. Other reports on the accident share this common assessment regardless of the wording. Even TEPCO, as the main party responsible for the accident, backed away from its initial excuse that the accident was caused by an "unexpected natural disaster" and admitted that there were man-made factors. The TEPCO representative also clearly acknowledged this fact in one of the IAEA's expert meetings in May 2013.

Recognizing the Fukushima Accident as a man-made disaster would mean the need to pay the closest of attention to various human factors; in other words, the level and quality of the prevailing nuclear safety culture with respect to the human, structural, and organizational aspects, as the indirect causes and underlying factors. Triggered directly by a huge natural disaster - giant earthquake and tsunami- the Fukushima Accident was complexly compounded by human factors (mostly omissions). This means that it should be understood as an unlucky major "complex disaster" and aspects of human factors should not be omitted or minimized alongside the discussions of natural factors.

\section{Three Mile Island and Chernobyl}

Human factors were also included as the main causes of the Three Mile Island (TMI) Accident that occurred in the United States (1979) and the Chernobyl Accident (1986). The President's Commission on the TMI, chaired by John G. Kemeny, made specific recommendations regarding necessary improvements, based on a detailed analysis of the accident's causes by identifying human, structural, and organizational problems and weaknesses in the safety regulation system that was employed in the United States at that time. This analysis went beyond findings of the operational mistakes made by the operators of the reactor. Eventually, after some twists and turns, the United States gradually implemented one recommendation after another to build up a robust regulatory system, including the reinforcement of the Nuclear 
Regulatory Commission (NRC). A comparison of the Kemeny Report and the Kurokawa Report, despite the differences in the scale and circumstances of each case, reveals many striking commonalities with respect to the human factors.

Aside from these commonalities, Japan probably has much to learn from the way the United States summed up its experiences from the TMI Accident, planned specific steps for its regulatory reform, and enhanced nuclear safety through a range of painstaking and steady reforms and improvements made by both the public and private sectors. For instance, the Institute of Nuclear Power Operations (INPO) was established as a mutual monitoring system by power utilities at their own initiative after much soul-searching over the TMI Accident. Together with the NRC, the INPO plays a unique role as an inseparable part of the system designed to ensure nuclear safety. It would be encouraging if such a system could take shape in Japan also. Japanese citizens may well be watching to see if not only TEPCO but Japan's power industry as a whole will adopt any decisive initiatives aimed at enhancing its self-corrective functions and safety culture, rather than just dismissing the Fukushima Accident as a one-off experience of a single company.

Restoration of a sound nuclear safety culture by the regulatory bodies and the power industry is an essential minimum step in regaining the public's trust. However, there are also many other genuinely important challenges that will need to be tackled in the future. They include, but are not limited to, redefining the roles of the national government, the relationship between the national government and host municipalities, and the optimal crisis management system. A preoccupation with the immediate tasks required to deal with the consequences of the Fukushima Accident cannot justify a rushed attempt at superficial soul-searching and reforms. The author expects that constructive discussions will initiate among the legislative and executive branches, the power industry, and civil society to produce some tangible outcomes. Clearly, measures adopted in one country may not fit the different conditions prevailing in another country. Nonetheless, good practices and worthwhile lessons from overseas should be considered for adoption in our country without hesitation.

\section{How Lessons are Learned Outside Japan}

Let us see how some countries and international organizations are trying to learn lessons from the Fukushima Accident.

\section{IAEA}

As the lead international agency for nuclear safety and regulations, the IAEA embarked on the drafting of a summary report on the Fukushima Accident. Experts are working under the leadership of Director General Yukiya Amano to complete this report by the end of 2014. Japan is also taking part in this project. The Fukushima Accident, along with the country report submitted to IAEA by Japan, is likely to draw particular attention at the next triennial Review Meeting of the Contracting Parties to the Convention on Nuclear Safety, to be hosted by the IAEA in March 2014.

\section{Europe}

In Europe, under the European Union and its framework the European Nuclear Safety 
Regulators Group (ENSREG), 14 member countries that have nuclear power plants began conducting their respective safety checks (stress tests), by assuming the occurrence of accidents triggered by natural phenomena. Those tests apparently did not disclose immediately any general issues that may directly impair the safety operation of the existing nuclear facilities. Nonetheless, they seem to have identified some points for improvement with respect to reinforcing measures against natural disasters. The results of the stress tests conducted in the respective countries have been subject to EU-wide peer reviews. These findings have been reported at meetings of the ENSREG, and each country is trying to reinforce its safety measures. For this reason, they maintain a keen interest in the lessons learned from the Fukushima Accident.

With regard to human factors, France-leading nuclear power in the EU-has established a working group on human, social, and organizational factors (HSOF) under France's regulatory body, the Autorité de Sûreté Nucléaire (ASN). They seem to be trying in their own way to apply the lessons learned from the accidents experienced in Japan to enhance nuclear safety in France and the rest of Europe.

\section{United States}

In the United States, the National Academy of Sciences has begun to extract reference cases related to the Fukushima Accident as requested by Congress. A report by the INPO and various other reports are being drafted. The NRC has also launched the Japan Taskforce with about 20 assigned personnel to extract reference cases and draw lessons from the accident.

\section{How Lessons Have Been Learned by Japan}

The swift and proactive attitude to learn from overseas accidents shown by the two leading nuclear powers - the United States and France-and other European countries demonstrate their strong sense of commitment to constantly enhancing their nuclear safety culture. Even before the Fukushima Accident, these countries actively sought to enhance their nuclear safety by taking heed of the lessons learned from the TMI and Chernobyl Accidents. By 2009, EU member countries and the United States had reportedly aligned their safety regulations with IAEA standards.

So, compared to them, how did Japan fare as the world's third largest nuclear power producer? Reports by the NAIIC and by other bodies have pointed out that, before the Fukushima Accident, Japan's regulatory authority tended to be inward-looking in its approach and did not make much effort to incorporate international standards and good practices from other countries. As a result, the country remained out of touch with the international trends and lagged behind others in terms of efforts to enhance nuclear safety. According to a well-informed commentator, Japan "found itself in an abnormal situation, a country that remained out of the loop."

A symbolical example of this is the way in which Japan chose to deal with a mission carried out by the Integrated Regulatory Review Service (IRRS) of the IAEA to conduct a peer review. Japan did host a mission as required in 2007, but it failed in taking the necessary action to follow-up on the mission's findings. Indeed, the Fukushima Accident occurred in March 2011, which exceeded the three-year timeline for hosting a follow-up mission as required, for improving the matters identified previously. 
In this regard, the NAIIC Report summarized the problem as follows: "The nuclear sector in Japan is strongly disinclined to disturb the status quo, clinging stubbornly to the existing nuclear safety system. The regulatory authorities and power utilities do not discuss what needs to be done to improve safety. Instead, they tend to focus on ways of convincing the public, the host communities, and the international community that existing measures are adequate to ensure nuclear safety."

Indicative of the prevailing attitude at that time, such an attitude epitomizes the degradation of Japan's safety culture. One must admit with deep remorse that the entire nation had to pay dearly for this failure in Fukushima. For this, all the stakeholders carry a grave responsibility. Clearly, it is vital for us to take this lesson to heart, put the previous attitude and mentality behind, and open up Japan's regulatory framework to the outside world. The NRA bears an important responsibility in leading these efforts.

\section{International Engagement by the NRA}

I would now turn to deal briefly with how the NRA has begun its international engagement, in particular on the $3 \mathrm{~S}$ measures.

\section{Cooperation with the IAEA-Early Hosting of IRRS and IPPAS Missions}

Japan and the IAEA are about to start the hosting of peer review missions. The first one will be a mission by the IRRS. Japan needs to make a fresh start given the afore-mentioned mistakes made in the past. The IAEA also wishes to have this mission take place at an early stage. NRA's Chairperson Shunichi Tanaka and IAEA's Director General Yukiya Amano have confirmed their agreement in principle for an early IRRS mission to Japan. The appropriate timing is to be decided so as to allow proper preparations and to ensure substantial outcomes by this mission. Once the new set of regulatory framework and standards are in place for nuclear safety, Japan must engage seriously with international peer reviews and apply their findings earnestly to enhance its nuclear safety.

The second peer review mission, which Japan should host at an early stage, is the International Physical Protection Advisory Service (IPPAS), also operated by the IAEA. IPPAS provides advice and assistance for improving and reinforcing frameworks for preventing nuclear terrorism (physical protection). So far, 30 countries, including the United States, France, and South Korea, have hosted these missions, yet Japan has failed to keep up with others in hosting it. Japan has announced its plan to host a workshop this year with the IAEA as part of prior preparations (as stated by the State Minister for Foreign Affairs at the ministerial meeting on nuclear security held this July, 2013), and preparatory work is underway.

\section{Reinforcement of Nuclear Security Measures}

The Fukushima Accident revealed how a station blackout at a nuclear power plant can trigger grave emergencies and where a plant's vulnerabilities lie. One lesson derived from the experience of Fukushima is the need for nuclear power state to take effective measures against acts of terrorism targeting nuclear facilities and nuclear material transportation. With this in mind, it is necessary to make every effort to implement nuclear security measures as well as nuclear safety. Nuclear terrorism should never be tolerated anywhere in the world, so heads of 
states have demonstrated their serous concerns about nuclear security at the 2010 Summit held in Washington, D.C. The next summit is to be held in the Hague, the Netherlands, in 2014, to be followed by another one in Washington, D.C. in 2016.

In Japan, nuclear security measures used to be implemented by various government bodies under the overall coordination of the Special Committee on Physical Protection under the auspices of Atomic Energy Commission. This coordination role has now been transferred to the NRA, and under its leadership the security measures must be reinforced based on the experiences gained to date. To enhance its nuclear security, Japan has incorporated in its own regulations, a set of international standards such as those contained in the relevant international treaties and IAEA recommendations. In terms of international treaties, following the ratification of the Convention on the Physical Protection of Nuclear Material in 1988, an early ratification of the amended Convention (2005) is envisaged.

Nonetheless, on nuclear security there are still matters of concern that must be addressed. For instance, the Nuclear Threat Initiative, an American NGO, ranked Japan 23rd out of 32 countries in terms of its overall international rating (as of January 2012). This poor rating seems to be associated with the large amount of nuclear materials stocked in the country and the absence of an independent regulatory body (at the time of the rating). Furthermore, Japan ranked near the bottom at 30th with respect to personnel-related measures for ensuring security. What is behind such a poor rating?

This rating is related to the issue of personnel-vetting as an important pillar in the prevention of internal threats. In line with an IAEA recommendation, personnel vetting has been adopted by all the major nuclear powers, except Japan. Our country has not dealt with this issue yet, which involves the protection of personal privacy, despite the widely acknowledged need for a storage and inquiry system for personal information in order to prevent internal threats by verifying the credibility of personnel and workers at a nuclear facility.

For this reason, the NRA has established a "Study Group on Nuclear Security" to introduce a personnel-vetting system and pursue tangible measures aimed at addressing other challenges (e.g. nuclear security measures during transportation as well as for radioactive materials and relevant facilities). The Study Group is examining specific measures and activities to implement them with the aid of external experts and the relevant ministries and agencies. The early hosting of the afore-mentioned IPPAS mission is also a part of these efforts.

\section{Safeguards Against Nuclear Proliferation}

Previously, safeguards-related work had been handled between the Ministry of Education, Culture, Sports, Science and Technology (MEXT) and the Ministry of Foreign Affairs (MOFA). In April 2013, this work was delegated to the NRA following a transfer of personnel from MEXT and of the necessary budget. From now on, the work will be handled by the NRA and MOFA. Japan has long been the second-largest contributor to the IAEA budget. Furthermore, the country has been by far the top target of IAEA safeguard measures, with about $30 \%$ of its human and financial resources allocated for Japan.

With this background, Japan and the IAEA have built up a relationship based on trust and close cooperation as an asset. As it embarks on a fresh start, the NRA should build on this asset to reinforce its cooperation with the IAEA on nuclear non-proliferation and do its best to ensure that its safeguard measures do not give rise to any mistrust or doubts. Going even further, it should intensify its international cooperation on nuclear non-proliferation in Asia and beyond, while taking full advantage of Japan's experience and technologies in nuclear safeguards. 


\section{Bilateral Relations with the US, France, the UK, Russia, and Other Countries}

Japan has maintained a certain level of bilateral relations focused on information sharing with other major nuclear powers. As the NRA began its fresh start, it signed memoranda of understanding with several countries in recognition of their needs to strengthen such cooperative ties.

To begin with, with the US and France, new arrangements were agreed to on the holding of regular meetings between the regulatory authorities of the respective countries (i.e., the US-Japan Steering Committee and the France-Japan Bilateral Committee, respectively). These meetings will be held both at the Commissioner level and the expert level to strengthen cooperation and partnership. A similar agreement with the UK is also under consideration. Russia has expressed a desire to strengthen its previously tenuous ties with Japan in the aftermath of the Fukushima Accident and a memorandum of understanding is expected in the near future.

These agreements are expected to intensify activities aimed at promoting information sharing, mutual visits of experts, and personnel exchanges as well as hosting seminars and workshops, and looking for opportunities for joint projects.

Under the US-Japan cooperation agreement for the peaceful use of nuclear energy, the NRA is looking to establish a new arrangement with the US Department of Energy to cooperate in $R \& D$ within their assigned jurisdictions. The establishment of new partnerships with the Nordic countries is also being considered.

\section{International Advisors}

After the Fukushima Accident, three internationally renowned experts have been commissioned as NRA's foreign advisors to seek advice from a broader international perspective based on their rich experience: Dr. Richard Meserve, the former chairman of the NRC in the United States; Dr. Mike Weightman, the former chairman of the Office for Nuclear Regulation (ONR) in the United Kingdom; and Dr. Andre-Claude Lacoste, the former chairman of the ASN in France.

\section{Conclusions}

What should Japan learn from the Fukushima Accident and how should it enhance its nuclear safety culture? Our challenges have just begun. It is imperative to overcome our hitherto inward-looking attitudes. There is no end to cultivating and improving a genuine safety culture. Aside from the continuous efforts required of all the stakeholders, it is essential that we change and reform the mindsets of power utilities, regulatory authorities, and citizens. The establishment of the NRA is just the starting point for this endeavor, not the finishing point. International efforts have been initiated as outlined above, but much has yet to be fleshed out and implemented.

As mentioned at the beginning, the Fukushima Accident led to a marked increase in the complexity and amount of work in international areas of assignments for the NRA and its Secretariat. As well, as a nation that caused a major nuclear accident, Japan must live up to higher expectations to share information with the international community properly. Japan obviously needs to bolster its operational system and human resource infrastructure to be able 
to provide the level of international engagement necessary to meet these needs and expectations.

This need is clearly acknowledged in the legislative process, reflected in the provisions of the Act for Establishment of the Nuclear Regulation Authority (June 2012). More specifically, Article 6 of the Act's supplementary provisions lists measures for the personnel of the NRA Secretariat, for those engaged in international assignments and other assignments, that ought to be swiftly carried out by the government. Examples of the measures include: ensuring adequate level of salaries and compensation; improvement of working conditions for the staff; ample sourcing of new recruits; proactive recruitment of talented individuals from universities, research institutes, and private companies; providing opportunities for staff training and learning through overseas studies, personnel exchanges, assignment to relevant international organizations, foreign regulatory agencies, and Japan's embassies; establishment of training facilities and building up of training capacity; and adequate budgetary appropriations for the NRA, etc. It should be stressed that these measures are necessary to recruit and retain talented personnel who are internationally minded and highly motivated. The Act also stipulates the integration of the Japan Nuclear Energy Safety Organization (JNES) into the NRA as a move intended to strengthen the expertise of regulatory bodies.

The Act may be said to be quite unique in the sense that in establishing a new organization, it sets forth in such detailed, clear targets and disciplinary directions related to the organization and its human resources. This is rather uncommon in Japan and is clearly a reflection of the legislature's strong expectations and hope for the new regulatory bodies that have been created after much soul-searching over the Fukushima Accident.

The real challenge, of course, lies in the steady and faithful implementation of these measures. Some are already being carried out, but efforts have yet to be exerted in earnest. Even though it may not be possible to catch up overnight with the level of the NRC in the US or the ASN in France, something more than just "business as usual" is required. Given the character of bureaucratic structure and culture in the Japanese government, focused political backup may be required to help push the cart along as charted in the Act. At the start, we all expect that those in the regulatory authorities and concerned government officials will exert their best efforts toward achieving the worthy objective.

\section{General References}

1) http://www.mofa.go.jp/policy/energy/fukushima_2012/index.html.

2) http://www.nsr.go.jp/english/data/20130422lff.pdf.

3) http://www.nsr.go.jp/english/data/20130620_presentation.pdf. 